\title{
Training Social Learning Skills by Collaborative Mobile Gaming in Museums
}

\author{
Jolien Schroyen, Kris Gabriëls, Kris \\ Luyten, Daniël Teunkens, Karel Robert, \\ Karin Coninx, Eddy Flerackers \\ Hasselt University - tUL - IBBT \\ Expertise Centre for Digital Media \\ Wetenschapspark 2 \\ 3590 Diepenbeek - Belgium \\ firstname.lastname@uhasselt.be
}

\author{
Elke Manshoven \\ Provincial Gallo-Roman Museum \\ Provincie Limburg \\ Kielenstraat 15 \\ 3700 Tongeren - Belgium \\ emanshoven@limburg.be
}

\begin{abstract}
The use of handheld computers as a tool to enrich the museum experience has found its way into many museums, opening up new possibilities to increase the attractiveness of museum visits, especially for youngsters. We developed a mobile guide framework that supports the creation of mobile guides and adheres to social-constructivist principles of learning. The mobile museum game we created with this framework aims at developing the social, cognitive and technical skills of the users. Large scale evaluations show the potential power of our approach to stimulate interaction between youngsters and to create a playful learning experience.
\end{abstract}

\section{INTRODUCTION}

A lot of teenagers perceive a traditional museum visit as a rather boring activity. They associate a museum visit with passive learning and being obliged to learn, instead of associating it with interactive and free-choice learning. In the ARCHIE project, we wanted to explore the possibilities of Personal Digital Assistants (PDAs) to enhance the learning experience and break through these common expectations of teenagers of a museum being dusty and boring. The partnership of the Gallo-Roman Museum of Limburg (Belgium) in this multidisciplinary research project was no coincidence. As part of a large expansion project, the museum conducted an extensive survey among (potential) visitors, to find out about their interests and to determine in which way they want to learn about the museum collection. One of the main target groups of the museum consists of schoolgroups on a field trip. Because most of the pupils who participated in the target group study indicated a strong interest in games and interactive media, we decided to use these interests in order to enrich their museum visit.

Permission to make digital or hard copies of all or part of this work for personal or classroom use is granted without fee provided that copies are not made or distributed for profit or commercial advantage and that copies bear this notice and the full citation on the first page. To copy otherwise, to republish, to post on servers or to redistribute to lists, requires prior specific permission and/or a fee.

Advances in Computer Entertainment Technology 2008, Yokohama, Japan. Copyright 2008 ACM 978-1-60558-393-8/08/12 ...\$5.00.
We set ourselves the objective to develop a collaborative mobile museum guide that provides a playful, interactive and social learning experience. To achieve these goals, we chose to focus on conveying the key messages of the museum narrative by means of mobile games. J.P.Gee [5] inspired us by posing the question "Why are youngsters willing to put so much time and effort in learning to play extremely complex video games?". According to Gee, the answer must be found in the "good principles of learning built into its design" that fit in with the skills needed for "the modern, high-tech, global world today's children and teenagers live in" [5, p.6-7]. We wanted to take this educational potential of computer games into account and create a mobile museum game that is "fun" and goes beyond mere information provisioning, a game that develops social, cognitive and technical skills.

The main contributions we present in this paper relate to the following. Firstly, by specifically designing to stimulate social interaction and collaborative gaming during the visit, we want to deal with the unintended side effect of many of the first PDA-based applications that bring about a quite individual and isolated museum experience [12]. Secondly, our game design is tailored to the museum content and to the target group to increase the learning performance. We try to use the motivation and interests of pupils for gaming and multimedia to create not only a profound learning experience, but also a fun one. Thirdly, we created a generic framework for museum guides that supports location-detection, personalization and communication.

\section{EVOLUTION IN THE USAGE OF MO- BILE GUIDES}

Over the last couple of years, the popularity of handheld computers as a tool to enrich the museum experience has increased. The strengths of this technology are clear: it allows for the dynamic presentation of information without disturbing the physical space, it provides the opportunity to access a wide range of different media (audio, video, text, photo, interactive games) and it enables visitors to browse information at their own pace and according to their own interests. Over the years we see a clear evolution in the way of putting these mobile guides to use within a museum context. At first, most mobile guides only offered additional information that was linked to the presented museum objects, much like the audioguides you can still find in many museums 
today. The only, yet important difference, is that mobile guides can also present (interactive) multimedia data to the visitor. In the evolution this medium has gone through from this phase onwards, we marked out following categories of mobile guides, based on a literature research on this topic and existing practices in mobile guides.

The first kind of mobile guide which goes clearly beyond the scope of traditional audioguides is the adaptive guide. These guides allow the user interface and content to be adapted to the context-of-use. One of the first attempts to develop adaptive guides was the Cyberguide [1] project. The PEACH project [6] focused on content adaptation based on the user's location, interests and the history of interaction between the user and the system. In later stages, several mobile guide implementations acknowledged the importance of narrative interfaces that allow the user to get immersed better in the historical context. Lim and Aylett [7] present a mobile guide in which the story presentation is adapted, based on the user's interests and opinions. In [9] the authors present a graph-based structure to describe how several "story parts" can be dynamically composed to form one integrated story for the visitor.

While early mobile museum guides only targeted the individual visitor and thus neglected the social aspects of a museum visit, in the last few years several ways of supporting interaction and collaboration were explored. The Sotto Voce project [13] introduces an 'eavesdropping' system that allows visitor-pairs to synchronize their audio tracks with one another. A next generation of mobile guides uses collaborative games to improve the museum visit and stimulate interaction. In the CoCicero project [3] visitors collect clues to solve a puzzle, shared with various co-visitors. The 'Mystery in the Museum'- game however [2], takes collaborative learning up to the next level: players do not only contribute to a shared puzzle, but are actually stimulated to exchange and discuss information.

Our work contributes to these latest evolutions in the usage of mobile guides to stimulate collaborative learning. The ARCHIE museum game considers social interaction and collaboration between pupils as the basic principle of the museum experience. Instead of aiming for a tool that offers the entire museum content to the visitor - be it by means of an adaptive system or not - we focus on conveying the key messages of the museum content through interaction: interaction between visitors, but also interaction with the museum environment and interaction with the mobile guide. How these interactions can be supported and stimulated by mobile guides built on our framework, is described in section 3.

\section{A FRAMEWORK FOR CONTEXT-AWARE MOBILE GUIDES}

The creation of our supporting framework that is used to build mobile guides is inspired by the concrete needs of a museum environment. Our aim was to add context-awareness were it is relevant to reach our goals. Starting point of our developments is the social-constructivist approach to learning in museums of Falk and Dierking [4], in which learning becomes a unique process for every visitor and in which the main objective of the museum is to provide the optimal con- ditions to stimulate this learning process. In their contextual model, the interactions and experiences visitors have in a museum are all influenced by three interweaving contexts: the socio-cultural context, the personal context and the physical context. The ARCHIE framework translates and connects the support for each of the three contexts into one unified framework. An overview of this framework is shown in Figure 1: it consists of a set of three core services on top of which an arbitrary interface can be deployed.

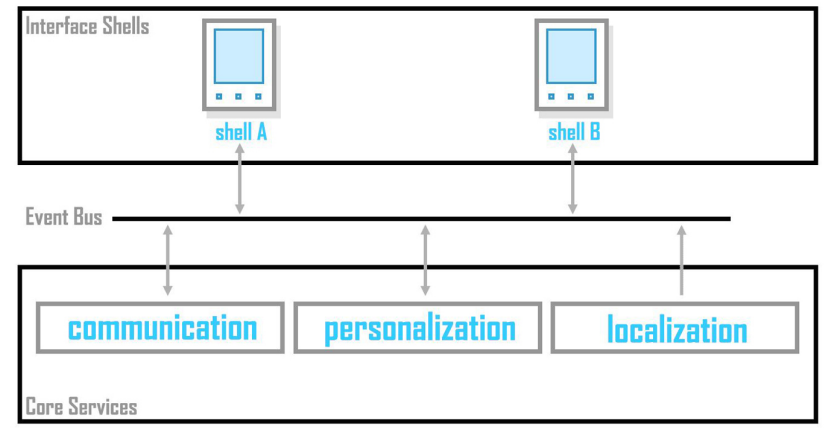

Figure 1: ARCHIE framework overview

The socio-cultural context is mainly supported by the communication module which allows visitors to communicate with each other. Direct communication between two or more visitors is provided using Voice-over-IP (VOIP) technology. The indirect communication encompasses all the data that need to be sent between the mobile guides to exchange their current states, so that they stay synchronized.

The physical context is supported by the localization module that allows to plugin different types of localization or proximity determination algorithms. In several of our developed games, WiFi-based localization is used, very much like presented in [14], since a wireless network needs to be deployed for the communication module anyway.

Finally, the personal context is supported by allowing different designs for different types of users on the one hand and by providing avatars to identify the visitor on the mobile guide on the other hand.

\section{DESIGN FOR PLAYFUL LEARNING}

An appropriate design process runs through different phases; starting from user analysis and concept generation towards implementation and evaluation. The main idea of UserCentered Design (UCD) is to involve the end-users of a product throughout the entire development lifecycle, from planning through post-release assessment, in order to guarantee a positive user experience (usability, accessibility, functionality,... $[8]$. In [11] we discussed our initial implementation of a UCD process. The results were satisfying, but did not take into account another important stakeholder: the host organisation who will use the mobile devices for their visitors. Therefore, we now tried to involve the museum staff in the different phases of our design process.

Based on the educational potential of computer games as described in $[5,10]$, we developed some principles that we used as a guide for the creation of our game design. Firstly, 


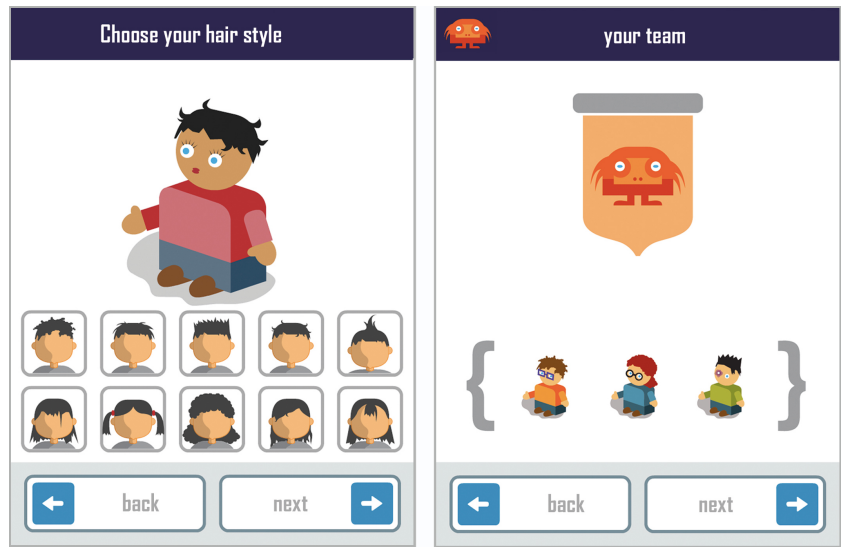

Figure 2: Adapting personal avatar (left) and avatar team (right)

we take great care that the key messages of the game reflect the key messages in the museum narrative. The museum content has to be learned by playing, without explicitly lecturing about content. Our mobile guide also attributes to gradually developing the skills the pupils need to play the game. Instead of providing youngsters with manual-like dry information about the game logic or PDA funtionalities for instance, we gradually increase the complexity of the tasks they have to fulfill.

Secondly, to promote a collaborative learning experience, group interactions and the various social skills that go with it, are stimulated throughout the entire museum game in different ways (communication by means of a walkie-talkie system, face-to-face communication, problem-solving strategies, division of tasks and the exchange of game information,... ). These group interactions also imply that the players feel like they are in control, wich is important to have a real game experience. The players can create their own experience by exploring their actions and the specific effects they cause.

Thirdly, to enhance the commitment of the players to the game, each player gets to adapt his/her own avatar which accompanies him/her throughout the entire museum game (Figure 2). Via these personalized avatars, the players can imagine themselves being in the historical circumstances we evoke during the games.

Finally, the graphical design of our mobile game is specifically tuned to the target group and reflects the museum content, thus stimulating learning history in a subconscious way. Games are for example located in a suitable landscape, given the relevant historical place and time (Figure $3)$. Given the fact that a museum visit should be an enjoyable activity, we use humorous elements that do not interfere with the museum content but emphasize it. Other graphical elements break through the expectations of the players and keep them alert. We explicitly chose to add these kind of triggers to stimulate interaction, both with companions and with the museum presentation.

\section{EVALUATION}
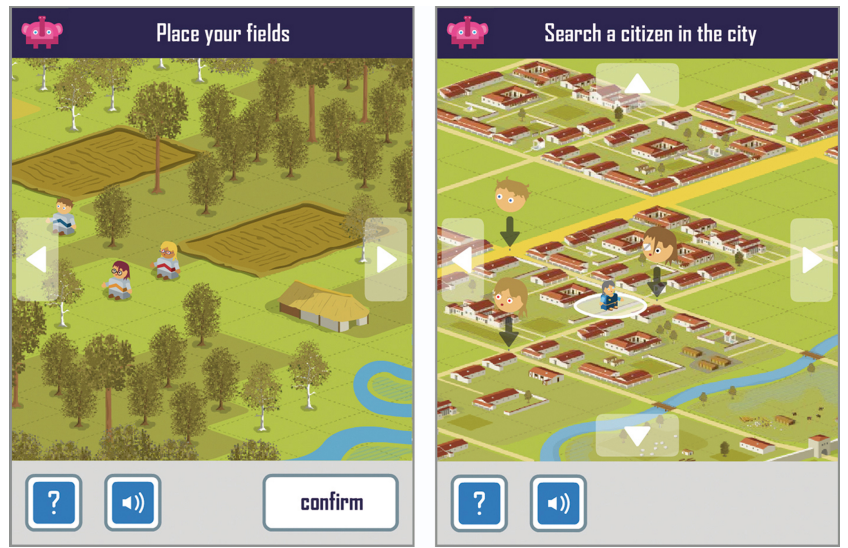

Figure 3: Screenshots of the game landscapes: farming landscape (left) and Roman city (middle)

Before putting everything in the target environment, an evaluation is required. We specifically evaluated the usability of the system and whether our design for playful learning produced the desired results. We evaluated if the game indeed provokes social interaction and interaction with the museum environment. Furthermore, we evaluated whether the targets regarding learning we postulated were obtained: if the key messages of the museum narrative were conveyed to the pupils by letting them relive the main episodes of the museum story for one thing, for another if the cognitive skills related to learning history and visiting a museum were trained. Finally, we wanted to acquire a notion of the motivation of the youngsters. In this section we will present our test set-up and results.

\subsection{Test Location and Participants}

Because of the ongoing expansion project in the target museum, we were unable to test our prototypes in the museum target environment. Therefore we visited four different secondary schools to organise extensive user tests in a simulated museum environment: posters of museum objects and - if on hand - some replicas that convey the museum content were displayed. Three prototypes have been tested: the trading game (tested by 68 pupils), the farming game (tested by 92 pupils) and the Roman game (tested by 137 pupils). We intended to reach a wide scope of the envisioned target group and thus tested a mix of pupils from general as well as technical and vocational secondary education. All participants were between 12 and 16 years old.

\subsection{Test Procedure and Instruments}

The schoolgroups were divided into teams of 3-4 players and every player recieved a PDA. Observation notes were taken and if the school and the parents consented, video recordings were made of a random sample of the available teams. After the game, the pupils were asked to fill in a questionnaire regarding computer usage, usability and playability of the game, learning results and motivation. The questionnaire consisted of about 20 multiple choice questions and Likert scales, and a limited number (about three to four) open ended questions. In addition to this, we also logged the user interactions on the PDA to analyse the course of the game. 


\subsection{Results}

As expected, the questionnaires showed that most of the teenagers were very familiar with ICT. As a result, these pupils were not put off by trying out a new ICT application, but on the contrary were rather excited to get their hands on a PDA. Although over $75 \%$ of the pupils declared that they had never used a PDA before, the same amount said it was (very) easy to use. We noticed that some functionalities of the game interface, such as using the walkie-talkie sytem or scrolling through the landscape, were not commonly known by the users: they gradually picked up these technical skills by trial and error and by discussing them with their peers. This proves the learnability of our mobile game.

The data collected from observation notes and video recordings demonstrate that our goals concerning interaction were obtained. There was generally a good balance between looking on the screen and looking at the simulated museum exhibit. Furthermore, the games clearly provoked collaboration and social interaction among its players. We even noticed that interaction was not only induced by the game sequences that were deliberately designed to stimulate collaboration and discussion, but also by some other aspects of the game design, such as the creation of their own personal avatar in the beginning of the game or the funny visuals and audio tracks.

With regard to the learning of the main messages of the museum content, the questionnaires showed that on average $70-75 \%$ of the participants answer the questions relating to the key content of the museum correctly. This key content was not explicitly lectured during the game, so we can conclude that the participants picked it up, simply by playing the game. Video recordings and observation notes also showed that the pupils did engage in the presupposed cognitive and observation skills, such as processing information from various sources and closely observing objects.

The observed behaviour and the questionnaire certainly confirmed the enhanced motivation of the youngsters. Over $90 \%$ indicate that they like the games. When asked what they think about the idea of using a PDA as a guide throughout the museum, $85-90 \%$ select "great, it makes a museum visit a lot more fun".

\section{CONCLUSION}

In this paper, we presented a mobile guide framework to support social-constructivist mobile guides. With a well thought-out process, we are able to create attractive, fun and informative collaborative mobile games. Our evaluation of the prototypes showed that mobile games that enhance the social relationships between visitors are an ideal tool to stimulate and motivate youngsters to visit a museum. This is especially true for pupils of technical and vocational secondary schools that are typically less motivated to visit a traditional museum or to learn about history or heritage in a traditional way. By means of our framework and our userand museum-centered design approach, we can increase the attractiveness of museum learning and heritage education for this target group that is often difficult to reach by the educational staff of museums and heritage sites.
Acknowledgments. Part of the research at EDM is funded by the European Regional Development Fund and the Flemish government. We would like to thank Heleen Van Loon who helped laying the foundations of this work and Mieke Haesen who shared her expertise in usability testing. We would also like to thank the following secondary schools in Limburg (Belgium) for cooperating in the evaluation process: O.-L.-Vrouwlyceum, Middenschool Kindsheid Jesu, Technisch Instituut St.-Lodewijk, and St.-Franciscuscollege .

\section{REFERENCES}

[1] G. D. Abowd, C. G. Atkeson, J. Hong, S. Long, R. Kooper, and M. Pinkerton. Cyberguide: a mobile context-aware tour guide. Wireless Networks, 3(5):421-433, 1997.

[2] J. S. Cabrera, n. F. Henar Mu A. G. Stoica, N. Avouris, Y. Dimitriadis, G. Fiotakis, and K. D. Liveri. Mystery in the museum: collaborative learning activities using handheld devices. In Proceedings of MobileHCI '05, pages 315-318. ACM, 2005.

[3] R. Dini, F. Paternò, and C. Santoro. An environment to support multi-user interaction and cooperation for improving museum visits through games. In Proceedings of MobileHCI 2007, pages 169-175, 2007.

[4] J. Falk and L. Dierking. Learning from Museums: Visitor Experiences and the Making of Meaning. Altamira Press, Walnut Creek, 2000.

[5] J. P. Gee. What Video Games Have to Teach Us About Learning and Literacy. Palgrave Macmillan, New York, 2003.

[6] I. Graziola, F. Pianesi, M. Zancanaro, and D. Goren-Bar. Dimensions of adaptivity in mobile systems: personality and people's attitudes. In Proceedings of IUI '05, pages 223-230. ACM, 2005.

[7] M. Y. Lim and R. Aylett. Narrative construction in a mobile tour guide. In International Conference on Virtual Storytelling, volume 4871 of Lecture Notes in Computer Science, pages 51-62. Springer, 2007.

[8] A. Moore and D. Redmond-Pyle. Graphical User Interface Design and Evaluation: A Practical Process. Prentice Hall PTR, Upper Saddle River, 1995.

[9] M. O. Riedl and R. M. Young. From linear story generation to branching story graphs. IEEE Computer Graphics and Applications, 26(3):23-31, 2006.

[10] R. Sandford and Ben Williamson (NESTA Futurelab). Games and learning. Bristol, 2005.

[11] H. Van Loon, K. Gabriëls, K. Luyten, D. Teunkens, K. Robert, K. Coninx, and E. Manshoven. Supporting social interaction: A collaborative trading game on pda. In Selected papers from Museums and the Web 200\%, pages 41-50, 2007.

[12] D. Vom Lehn and C. Heath. Accounting for new technology in museum exhibitions. International Journal of Arts Management, 7(3):11-21, 2005.

[13] A. Woodruff, P. M. Aoki, A. Hurst, and M. H. Szymanski. Electronic guidebooks and visitor attention. In Proceedings of 6th International Cultural Heritage Informatics Meeting, pages 437-454, 2001.

[14] M. Youssef and A. Agrawala. The horus wlan location determination system. In MobiSys '05: Proceedings of the 3rd international conference on Mobile systems, applications, and services, pages 205-218. ACM, 2005. 